7-15-2021

\title{
Meeting the moment: The gender and education community's response to COVID-19
}

Evidence for Gender \& Education Resource (EGER)

Follow this and additional works at: https://knowledgecommons.popcouncil.org/departments_sbsr-pgy How does access to this work benefit you? Let us know!

\section{Recommended Citation}

Evidence for Gender \& Education Resource (EGER). 2021. "Meeting the moment: A snapshot of the gender and education community's response to COVID-19," EGER Research Brief. New York: Population Council. 


\section{MEETING THE MOMENT}

The gender \& education community's response to COVID-19

\section{WHAT'S INCLUDED?}

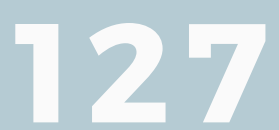

COVID-19 GIRLS'

EDUCATION PROGRAMS

Of these programs..

$\begin{array}{cc}\mathbf{7 7} \% \text { are newly } & \begin{array}{c}\mathbf{2 3} \% \text { are } \\ \text { adapted } \\ \text { from } \\ \text { existing } \\ \text { programs }\end{array} \\ \end{array}$

\section{Program Type}

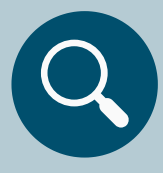

RESEARCH PROJECT

$33 \%$

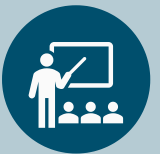

PROJECT/ PROGRAM

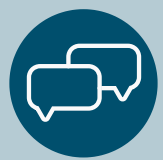

ADVOCACY CAMPAIGN

$27 \%$

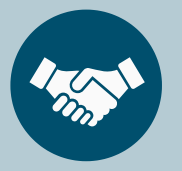

FUNDING INITIATIVE

$8 \%$

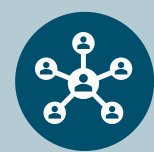

NETWORK/ CONVENING

$5 \%$

Regional Distribution

GLOBAL

$48 \%$

SUB-SAHARAN AFRICA

$41 \%$

SOUTH ASIA

$17 \%$

MIDDLE EAST \& NORTH AFRICA

$12 \%$

EAST ASIA \& PACIFIC

$6 \%$

LATIN AMERICA \&

$2 \%$

\section{COVID-19: How have we responded?}

Across the globe, the COVID-19 pandemic continues to disrupt girls' education. With sudden school closures, social gathering restrictions, and shifting funding priorities, organizations have had to halt, adapt, or create new girls' education programming to meet the challenges of this moment. It is more important than ever to coordinate our efforts to ensure girls receive a quality education as we navigate the pandemic's complex effects. To target COVID-19 response efforts effectively and efficiently, we must first understand who is doing what and where in the global gender and education ecosystem.

This is an initial snapshot of global COVID-19 girls' education activities as of April 2021. You can explore COVID-19 girls' education programs and find the latest evidence on gender and education in the EGER web-portal.

\section{Who are COVID-19 girls' education programs trying to reach?}

TARGET POPULATION

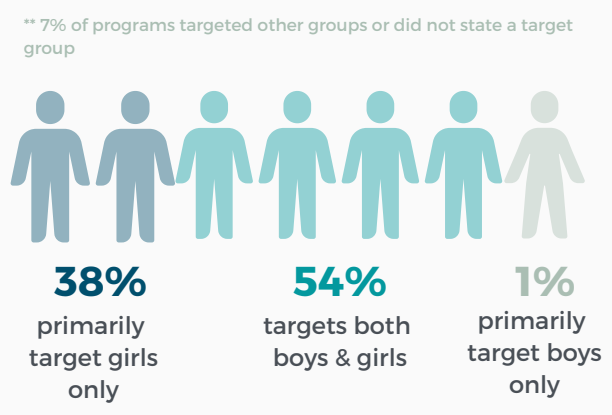

of programs include female and/or male teachers as a primary target group

\section{FREQUENTLY TARGETED SUB-POPULATIONS}

$\begin{array}{ll}\text { Displaced/refugee - Internal } & \mathbf{7 \%} \\ \text { Displaced/refugee - External } & \mathbf{6 \%} \\ \text { People with disabilities } & \mathbf{6 \%} \\ \text { Orphans \& vulnerable children } & \mathbf{2 \%} \\ \text { Other } & \mathbf{2 \%}\end{array}$

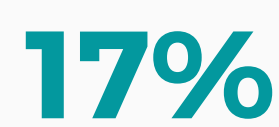

PARTICIPANTS' SCHOOL-LEVEL

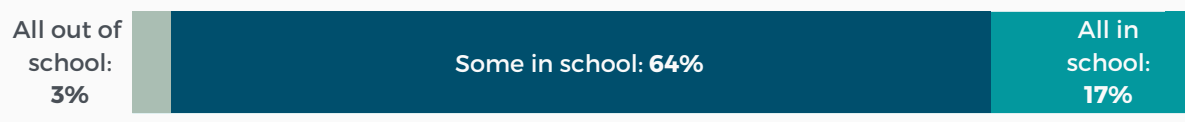




\title{
How are programs getting girls back in school and learning?
}

\author{
BOTH PROGRAMS THAT ADDRESS GIRLS' LEARNING AND PROGRAMS THAT ADDRESS \\ ENROLLMENT/ATTAINMENT MOST COMMONLY USE THESE FIVE APPROACHES:
}

Programs to improve enrollment/attainment
Programs to

improve learning
1

TEACHING MATERIALS

2

DIGITAL LEARNING DEVICES

3 DIGITAL LEARNING MATERIALS

4 COUNSELING/ SUPPORT IN/AROUND SCHOOLS

5 ALternative LEARNING CENTERS/ MOBILE SCHOOLS/ HOME SCHOOLS
$46 \%$

$43 \%$

$43 \%$

$39 \%$

$38 \%$
$60 \%$

$58 \%$

$57 \%$

$48 \%$

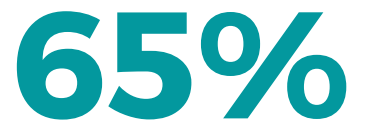

of programs that aim to improve learning use at least one EdTech approach
TECHNOLOGIES USED BY GIRLS' LEARNING PROGRAMS:

- Digital learning materials - Educational radio/

- Digital learning devices

- Digital textbooks

- Digital reading materials (non-textbook)

- Digital skills building/literacy (including coding)

\section{WHAT OTHER GOALS DO COVID-19 PROGRAMS AIM TO ACHIEVE?}

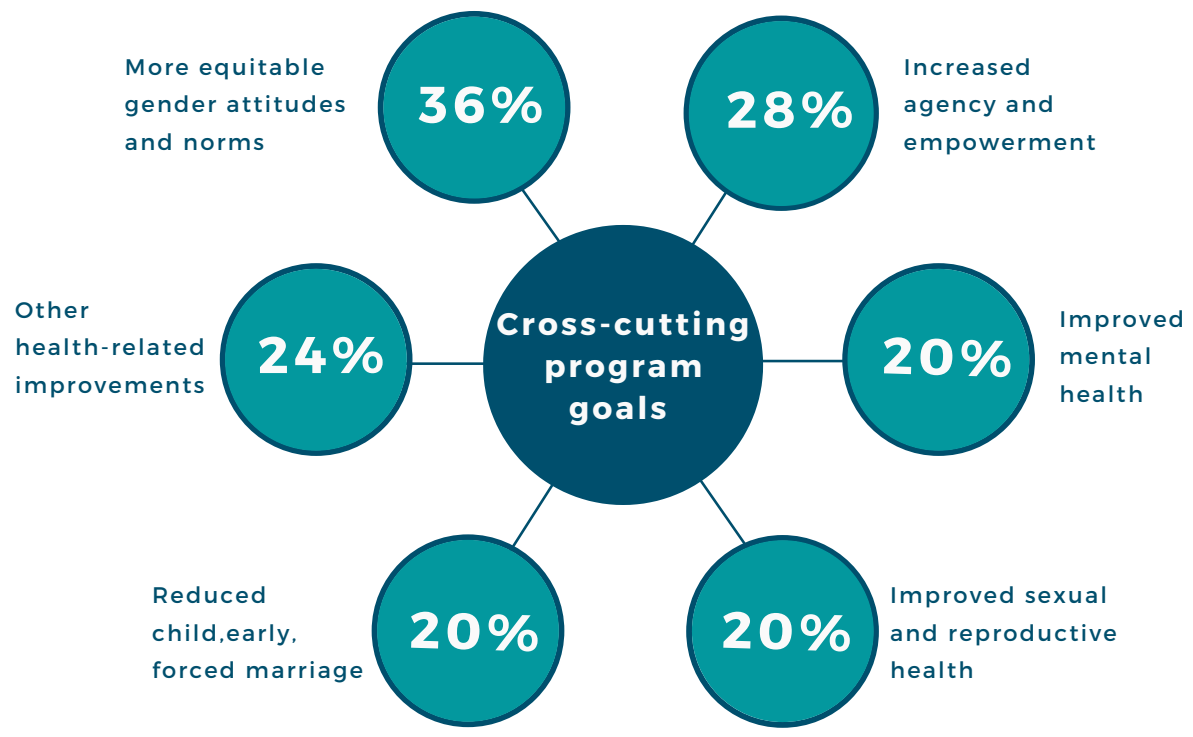

\section{Our Methodology}

\author{
EGER Program Criteria: \\ - Program is implemented in a \\ low-/middle-income country \\ - Girls' education is a stated program goal

\section{Methods}

We assessed $280+$ global organizations currently included in the Evidence for Gender and Education Resource (EGER) database and gathered information on their COVID-19-response girls' education programs. The EGER database does not currently include country-level government or local-level NGO programs and thus are not reflected in this brief.

For more information on who's included in the EGER database, and how we are expanding to include country-level programs, checkout our website at www.egeresource.org. 


\section{Q How are programs addressing other barriers to girls' education that may be worsened by the pandemic?}

\section{Child Marriage \& Early Adolescent Childbearing}

\section{$24 \%$}

address child marriage and/or early adolescent childbearing in their work

Of these programs..

$13 \%$

only

address child

marriage

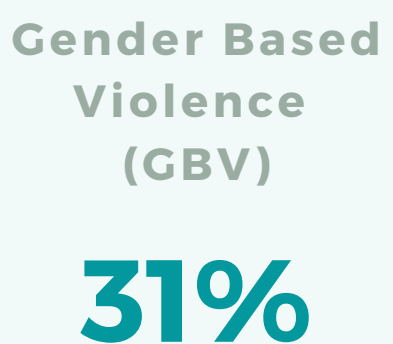

address violence in their programming

\author{
Water, Sanitation \& \\ Hygiene \\ (WASH)

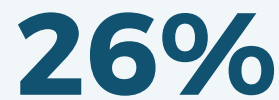

identify WASH as a cross cutting topic addressed in the program

Of these programs, the most commonly following approaches:

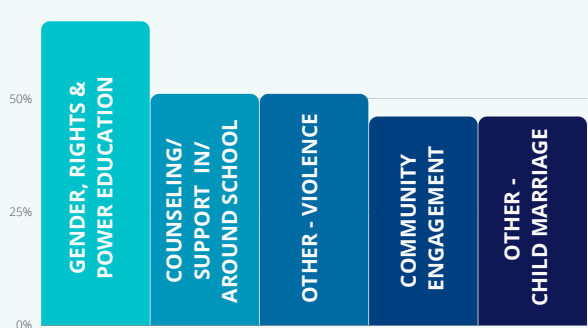

(Includes multiple forms of violence: SRGBV, violence-unspecified, intimate partner violence, and violence against children) implemented WASH approaches are:

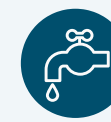

IMPROVED WATER

ACCESS

$18 \%$

(4)

DISTRIBUTED

MENSTRUAL HYGIENE

$12 \%$

PRODUCTS

CONSTRUCTED

/IMPROVED SEX-

SPECIFIC TOILETS

\section{How do we build back better during and after COVID-19?}

\section{Collect and disaggregate data}

As data emerge on COVID-19-related effects on returning to school and learning loss, it will be critical to ensure data are collected and disaggregated by gender, age, geography, and economic status. Disaggregated data on education and related needs of students together with documentation of current activities, will help us understand where gaps exist, who is being left behind and where investments need to be made.

\section{Evaluate COVID-19 girls' education programs}

It is vital to evaluate COVID-19 gender and education programs to assess what programs are improving which outcomes for whom, and to facilitate adaptive learning in the face of COVID-19's complex and ongoing challenges.

\section{Ensure evidence and practice are aligned}

Programs that address economic barriers to schooling are effective in improving enrollment/attainment before COVID-19 (see Girls' Education Roadmap). However, these approaches do not rank in the top five approaches of programs documented here. In contrast, provision of digital materials and devices figure prominently among strategies employed. Evaluations of these programs are not yet published and will be critical to assess their effectiveness and reach, as well as to build the evidence base on what does and does not work.

\section{Are you in?}

Join hundreds of organizations and share your work in the EGER database. To get started, visit https://egeresource.org/signup/

\section{Stay Updated!}

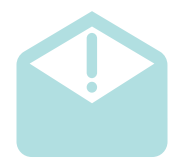

Receive the EGER Digest and get the latest evidence, updates, and data from the gender and education community. Sign up here!

\section{Suggested citation}

